\title{
Design and Simulation of Wide Band Fish Shaped UWB Antenna
}

\author{
Siddharth Bhat ${ }^{1}$, Rashmi Pattoo ${ }^{2}$ \\ ${ }^{1} U . G$ Student of Department of ECE, AIMT, INDIA \\ ${ }^{2}$ Assistant Professor, IILM, Gr. INDIA
}

\begin{abstract}
The Simulated antenna is one of the best antenna structures, due to its low cost and compact design .In the paper, we present a new research approach to improve the radiation effectiveness and the performance of antennas by miniaturization of the size. We have studied the performance of microstip patch antenna which consists of a fish shaped patch.This study was made for the wide frequency ranging from $5.3 \mathrm{GHz}$ to $9.1 \mathrm{GHz}$ and the geometory of the antenna and the results are obtained using the simulation software HFSS.The detailed design and the results are shown and disussed in this paper.
\end{abstract}

Key Words: Broadband, Microstrip, Patch Antenna, Planar, Ultra Wide Band

\section{Introduction}

Developments in communication systems Ultra Wide Band (UWB) in recent years has harnessed important research activity dedicated to antenna wide bandwidth [1], [2], [3]. This technology is based on ssssignals from the baseband which their band is not limited, of course levels of spectral densities; they must be limited not to interfere with present systems. The Federal Communications Commission (FCC) issued UWB Regulations, under Part 15 of Commision's Rules.[1]According to these rules, UWB signals may be transmitted between $3.1 \mathrm{GHz}$ and $10.6 \mathrm{GHz}$ at the effective isotropic radiated power (EIRP) levels up to $-41 \mathrm{dBm} / \mathrm{MHz}$ for the unlicenced use of commercial UWB communication systems.[4]Hence, up to $7.5 \mathrm{GHz}$ of bandwidth is needed for a workable UWB antenna. And commonly, the return loss for the entire ultra-wide band should be in the criterion of less than $-10 \mathrm{~dB}$. Next, for indoor wireless communication, omnidirectional property in radiation pattern is required for UWB antenna to enable convenience in communication between transmitters and receivers. Therefore, low directivity is preferred and the gain should be as uniform as possible for different directions.

UWB technology is mainly employed for indoor and portable devices, the size of the UWB antennas is required to be minimally small so that they can be easily integrated into various equipments. Thus, a major challenge for ultra-wideband communications (UWB) terminals for small or very small, for short range radio and in combination with sensors or networks of information transfer in the context domestic, multimedia or professional. The low power consumption (and thus performance), ease of integration, and especially the cost are essential parameters that are incompatible with the performance [5].

A brief overview of the UWB antenna design is given in this paper. We propose a micro strip-patch antenna which consists of a fish-shaped patch fed by a $50 \Omega$ impedance feeder. The advantages offered by this antenna, consists of its small size and simple structure easing the manufacturing. This paper is organized as follows: in the second chapter the short introduction. The third chapter gives UWB antenna design requirements and the fundamental limitations on antenna size and performance are described. The fourth chapter gives design and simulation results. The fifth chapter concludes the paper.

A. UWB Antenna Design Requirements

\section{Uwb Antenna Design}

The UWB antenna requirements are:

1. The UWB antenna must operate in frequency range from $3.1 \mathrm{GHz}$ to $10.6 \mathrm{GHz}$. [1] Therefore, UWB antenna impedance must achieve $7.5 \mathrm{GHz}$ bandwidth in order to avoid a large return loss and matching problem.

2. The UWB antenna should have linear phase through frequency range and constant group delay for the given frequency range. This means that UWB antenna should have as less as possible dispersion of pulses. [6]

3. An omni-directional radiation pattern is desirable because of user mobility and freedom in the transmitter or receiver position. Omni-directional radiation pattern means that the signal waves passing through antenna shall be able to travel in all directions. This implies minimizing UWB

4. antenna gain and directivity for use in communication systems.

5. The radiation efficiency must be very high as the transmit power spectral density is very low. The upper limit define by FCC is $-41 \mathrm{dBm} / \mathrm{MHz}$. [1] Conductor and dielectric losses should be minimized in order to maximize radiation efficiency. [6] 
6. The antenna is required to be physically compact and low profile, preferably planar. The antenna size should be small (comparing with wavelength) and, if possible not too heavy, but in the other hand very compact and robust. This requirement is due to small size of UWB devices and required user mobility

\section{B. UWB Antenna Size Limitation}

There are certain limitations regarding the size of antenna and efficiency of radiation for broadband antenna. The fundamental limitation of antenna size is called Chu- Harington limit [7] and was later reviewed by Mclean [8]. Chu set the theory of fundamental limitation for electrically small and omni-directional antenna. He assumed that every electrically small antenna with whatever geometry and current distribution can lie within boundary sphere. The fields outside boundary sphere must be exactly the same as with an ideal point dipole. Electrically small antenna is antenna that operates on frequencies which wavelength are much greater than antenna size. Chu calculated the lowest quality factor $\mathrm{Q}$ for a fixed size boundary sphere with radius $\mathrm{R}$ which gives the broadest bandwidth. Latter Chu results for quality factor $\mathrm{Q}$ was reviewed by McLean. The quality factor Q set limits to antenna where performance may be extended to the ultra wideband context with two observations: first center frequency ( $\mathrm{fC}$ ) is the geometric average of the upper ( $\mathrm{fH}$ ) and the lower ( $\mathrm{fL}$ ) frequencies and bandwidth is defined by the half power or $-3 \mathrm{~dB}$ points. $[6,8]$

The quality factor is given in formula (1)

$$
Q=\frac{f_{C}}{B W}=\frac{\sqrt{f_{H} \cdot f_{L}}}{f_{H}-f_{L}}
$$

The McLean limit is given in formula (2).

$$
Q=\frac{1}{k^{3} \cdot R^{3}}+\frac{1}{k \cdot R}
$$

Where $k$ is the wave number $(k=2 \pi / \lambda C)$ and $R$ is radius of boundary sphere. The McLean limit given in formula (1) gives connections between frequency bandwidth, antenna size and antenna radiation efficiency. The formula (1) gives connection between frequency bandwidth and antenna performance Q.

\section{Uwb Antenna Design}

Maxwell equations [9] are used in analysis of the UWB antenna as well as narrowband antenna but in the case of the UWB antenna it could not be simplified due to wide frequency range. Therefore the simulations are used during design and modeling of the UWB antenna. In this paper HFSS [10] is used.. Lumped Port is used as excitation signal. During the UWB antenna modeling process the fundamental limitations [7, 8] and the frequency-independent principles [11] should be considered.

\section{Design And Simulation Results}

The antenna proposed is composed of a ellipse patch-shaped ring and printed on a substrate (FR4) having a length $\mathrm{Lsub}=20 \mathrm{~mm}$ and $\mathrm{Wsub}=15 \mathrm{~mm}$ width. The relative permittivity of 4.4 and thickness of $1.5 \mathrm{~mm}$. The antenna is fed by a microstrip line of $50 \Omega, 10 \mathrm{~mm}$ length and width $\mathrm{w}=1.5 \mathrm{~mm}$, all placed on a ground plane of $15 \times 8 \mathrm{~mm}^{2}$ dimension as shown in Fig.1. Patch ellipse with a triangle constitutes the radiating element of the antenna. The design and study of the proposed antenna with a bandwidth of operation below - 10dB, which extends from 5.35 to $9.16 \mathrm{GHz}$, are presented.

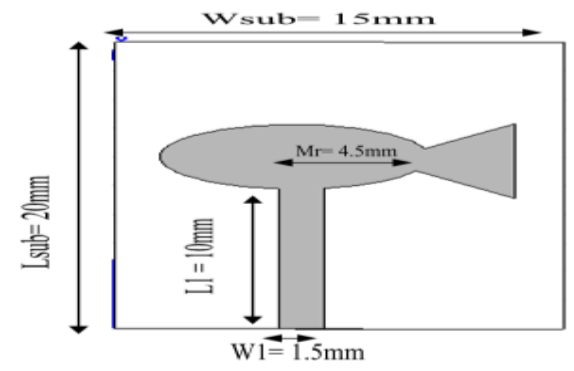

(a)

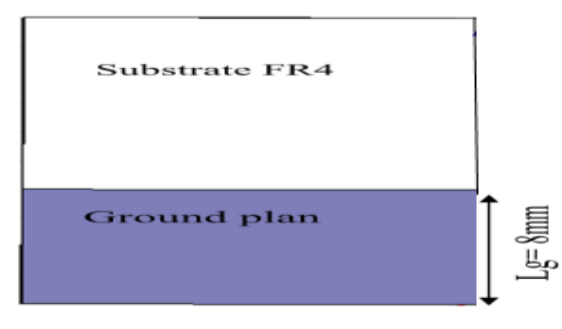

(b)

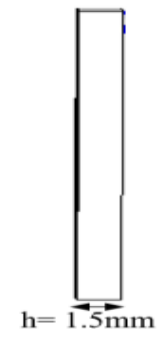

(c)

Fig 1 Proposed Antenna (a) Top View (b) Bottom View (c) Side View 
The proposed antenna was analyzed and optimized with the help of High Frequency Structure Simulator software. The simulation results of the return loss (in $\mathrm{dB}$ ) for this proposed antenna are shown. It is indicates that the proposed antenna cover $5.3 \mathrm{GHz}$ to $9.1 \mathrm{GHz}$, that is some portion of UWB. Here the maximum return loss is found $-27 \mathrm{~dB}$ at

$6 \mathrm{GHz}$. The bandwidth obtained from this graph is $3.8 \mathrm{GHz}$. Here are obtained the lower cutoff frequency $5.3 \mathrm{GHz}$, upper cutoff frequency $9.1 \mathrm{GHz}$ and the efficiency $23 \%$.

To measure the SWR of the antenna we use S11 parameter.. We found that the antenna had a $-10 \mathrm{~dB}$ or lower response in the bandwidth of $5.3 \mathrm{GHz}-9.1 \mathrm{GHz}$.

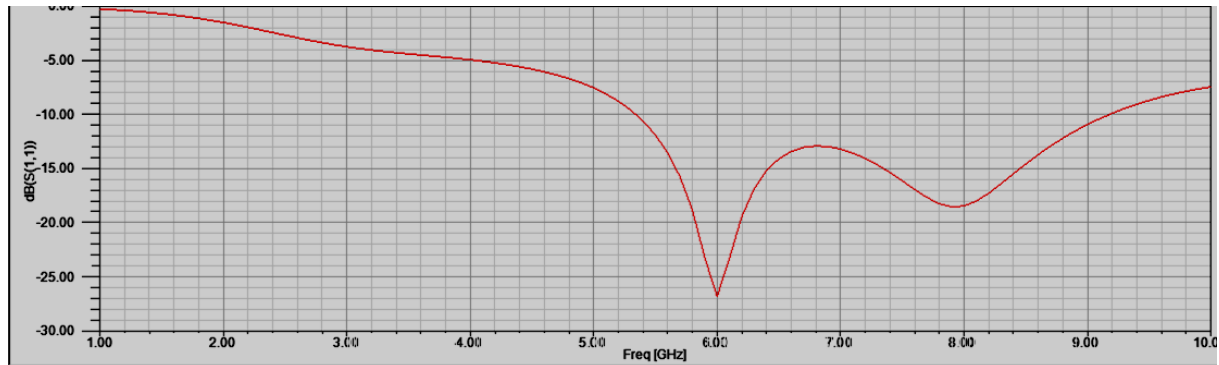

Fig 2 : The return loss $\mathrm{S}_{11}$ of the proposed antenna at $\mathrm{L} 1=10 \mathrm{~mm}, \mathrm{~W} 1=1.5 \mathrm{~mm}, \mathrm{Lg}=8 \mathrm{~mm}$.
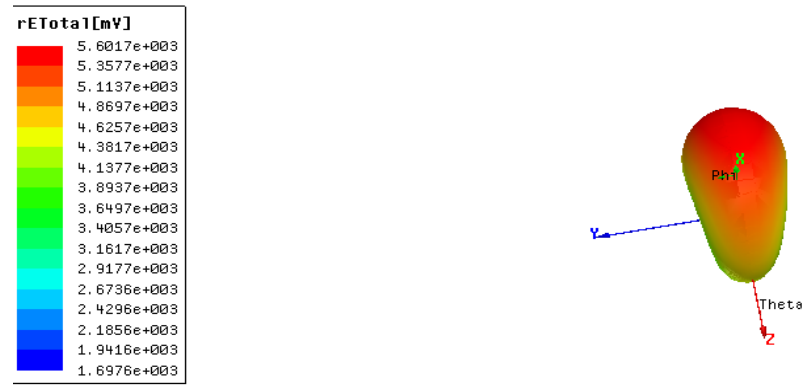

Fig 3 : 3-D Radiation Pattern

The above figure shows the radiation pattern in 3D format which indicate the highly directivity radiation pattern which has very small side lobes. The radiation patterns of the proposed antenna are also investigated. The $2 \mathrm{D}$ radiation patterns of proposed antenna for different frequencies are shown in fig 4 , fig 5 and fig 6. These figures shows that the simulated total field radiation patterns at $5.5 \mathrm{GHz}, 6.5 \mathrm{GHz}$ and $7 \mathrm{GHz}$. The proposed antenna is characterized by a quasi-omnidirectional pattern in the combination of E-plane and $\mathrm{H}$ plane. It can be seen that the excellent wide band radiation patterns are observed.

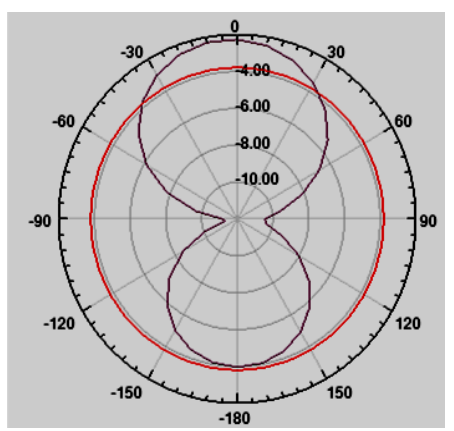

Fig 4 :2d Radiation pattern at $5.5 \mathrm{GHz}$

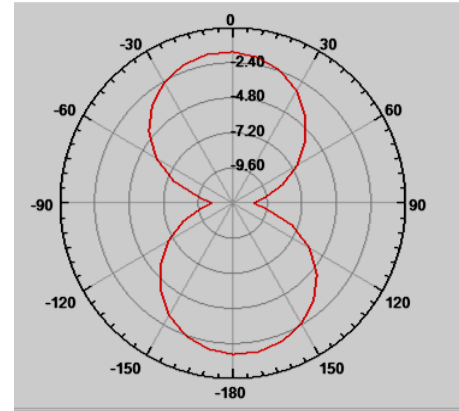

Fig 5 :2D Radiation pattern at $6.5 \mathrm{GHz}$ Fig 6: 2D Radiation pattern at $7 \mathrm{GHz}$

For the proposed antenna, two principle planes are selected to present the radiation pattern. These are referred to as the $x-y$ plane ( $E$-plane) and the $y-z$ plane (H-plane). This shows the plots of the normalized simulated radiation patterns in the $E$-plane and $H$-plane at several frequencies. In the $E$-plane, the value of azimuth angle of $0^{\circ}, 90^{\circ}, 180^{\circ}$ and $270^{\circ}$ while for the $H$-plane the value of elevation angle of $0^{\circ}, 90^{\circ}, 180^{\circ}$ and $270^{\circ}$ are taken into consideration. 
The below figure 7 shows the radiation pattern of E plane that is known as elevation plane or $\mathrm{x}-\mathrm{y}$ plne at an elevation angle of $0^{\circ}$ and it comes to be omnidirectional,at $90^{\circ}$ it is more wide at this angle. Radiation pattern at $6 \mathrm{GHz}$ frequency at angle. At an elevation angle of $180^{\circ}$ and it is becoming more directive.and at an elevation angle of $270^{\circ}$ and it is becoming more wide at this angle.

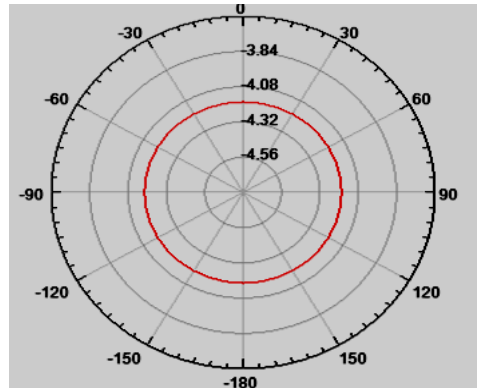

(a)

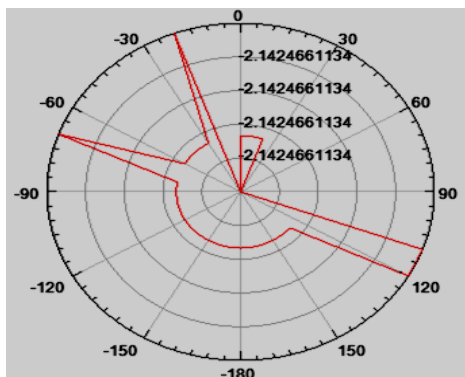

(c)

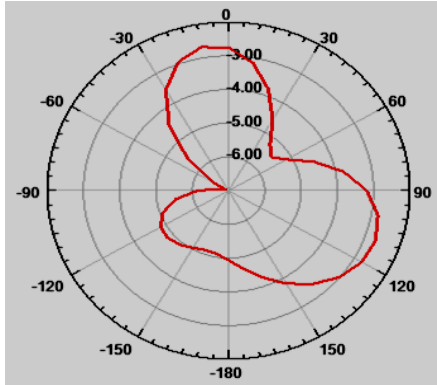

(b)

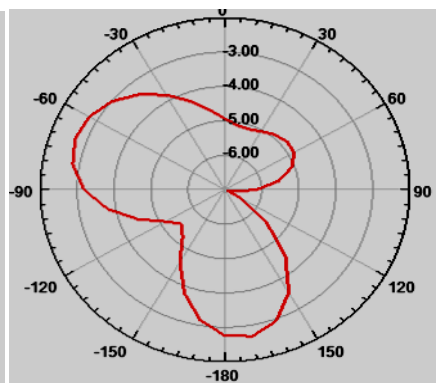

(d)

Figure 7:E Plane Radiation pattern at $6 \mathrm{GHz}$ frequency at (a) $\theta=0^{\circ}$

(b) $\theta=90^{\circ}$

(c) $\theta=180^{\circ}$

(d) $\theta=270^{\circ}$

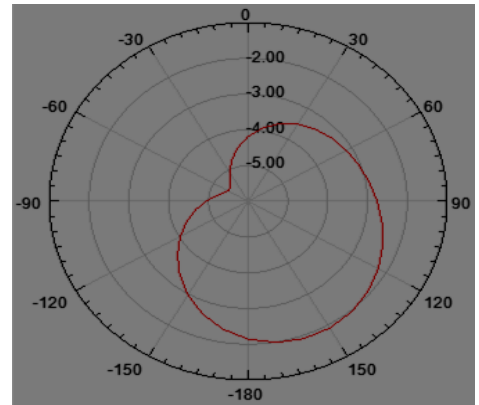

(a)

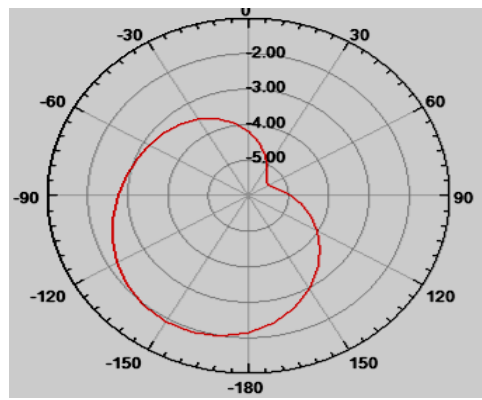

(c)

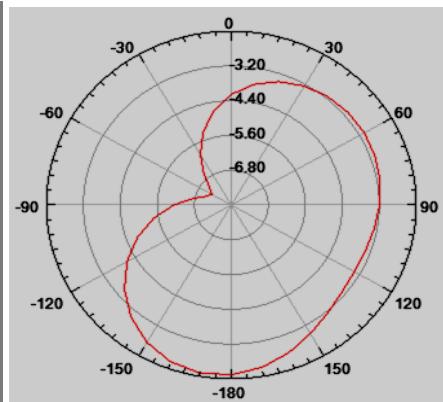

(b)

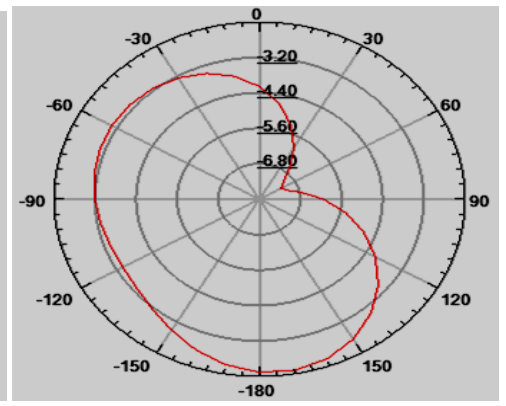

(d)

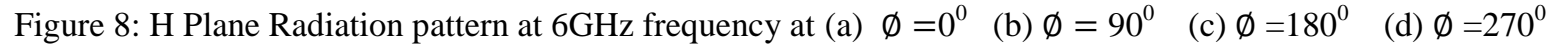
The above figure 8 shows the radiation pattern of $\mathrm{H}$ plane that is known as azimuth plane or $\mathrm{y}-\mathrm{z}$ plne at an azimuth angle of $0^{\circ}$ and it comes to be directional. at $90^{\circ}$ it is directional with side lobes, at $180^{\circ}$ it is again directional but in other direction and at $270^{\circ}$ it is directional with side lobes in different direction. 


\section{Conclusion}

Since the release by the Federal Communications Commission (FCC) of a bandwidth of $7.5 \mathrm{GHz}$ (from3.1GHz to $10.6 \mathrm{GHz}$ ) for ultra wideband (UWB) wireless communications, UWB is becoming popular as a high data rate wireless communication technology. As is the case in conventional wireless communication systems, an antenna also plays a very vital role in UWB systems. Studies have been done covering the areas of UWB basics and antenna theory. Extensive investigations were also carried out on the expansion of UWB antennas from the past to present. First, the antenna designs for UWB system is introduced and described. Next, the special design considerations for UWB antennas were discussed and summarized. In addition, a state-of-theart for the design of a UWB antenna with a bandwidth ranging from $5.3 \mathrm{GHz}-9.1 \mathrm{GHz}$ was discussed, which fulfill the system requirements for WiBro, WLAN and mobile phones.

\section{References}

[1] Christophe DELAVEAUD, “Antennas compacts pour les systèmes de communication Ultra Large Bande”, Institut de Microélectronique, Electromagnétisme et Photonique, France, 2009.

[2] Mohammed Younssi, Achraf Jaoujal, M. H. Diallo Yaccoub, Ahmed El Moussaoui, and Noura Aknin, "Study of a Microstrip Antenna with and Without Superstrate for Terahertz Frequency," International Journal of Innovation and Applied Studies, vol. 2, no. 4, pp. 369-371, April 2013.

[3] Tajeswita Gupta and P. K. Singhal, "Ultra Wideband Slotted Microstrip Patch Antenna for Downlink and Uplink Satellite Application in C band," International Journal of Innovation and Applied Studies, vol. 3, no. 3, pp. 680-684, July 2013.

[4] U.S.47 C.F.R. Part15 Subpart F 15.503d Ultra-Wideband Operation (October 1, 2003 edition).

[5] M. I. Hasan and M. A. Motin, "New slotting technique of making compact octagonal patch for four band applications," International Journal of Innovation and Applied Studies, vol. 3, no. 1, pp. 221-227, May 2013.

[6] Schantz, Hans:"The Art and Science of Ultra-Wideband Antennas", Artech House, 2005.

[7] Chu, L. J. "Physical Limitations of Omni-Directional Antennas". Journal of Applied Physics, v. 19, Dec. 1948, pp. 1163-1175.

[8] McLean, J. "A Re-Examination of the Fundamental Limits otheRadiation Q of Electrically Small Antennas". IEEE Transactions on Antennas and Propagation, v. 44, n. 5, May 1996, pp 672-675.

[9] Stutzman,W. L., Thiele, G. A.: “Antenna Theory and Design” second edition, John Wiley \&Sons, Inc.

[10] Rumsey, Victor H., "Frequency Independent Antennas", IRE National Convention Record, August 1958,pp 251-259.

[11] Rahul Yadav, "A Novel Approach for Gain and Bandwidth Re-Configurability in Helical Antenna," International Journal of Innovation and Applied Studies, vol. 4, no. 1, pp. 233-238, September 2013.

[12] J.D. Dyson, "The Unidirectional Equiangular Spiral Antenna," IRE Trans. Antennas Propagat., Vol. AP-7, pp. 329-334, October 1959.

[13] Ross, G.F., 1968, A time domain criterion for the design of wideband radiating elements, IEEE Trans. Antennas Propagat., Vol. 16, No. 3, p. 355.

[14] Dr. Tarance W. Barrett. History of Ultra Wideband (UWB) Radar \& Communications: Pioneers and Innovators. 